This item was submitted to Loughborough's Research Repository by the author.

Items in Figshare are protected by copyright, with all rights reserved, unless otherwise indicated.

\title{
Effect of dispersant concentration with friction modifiers and anti-wear additives on the tribofilm composition and boundary friction
}

\section{PLEASE CITE THE PUBLISHED VERSION}

https://doi.org/10.1115/1.4050017

\section{PUBLISHER}

American Society of Mechanical Engineers

VERSION

AM (Accepted Manuscript)

\section{PUBLISHER STATEMENT}

This paper was accepted for publication in the journal Journal of Tribology and the definitive published version is available at https://doi.org/10.1115/1.4050017.

LICENCE

CC BY 4.0

\section{REPOSITORY RECORD}

Umer, Jamal, Nick Morris, Ramin Rahmani, Homer Rahnejat, Sebastian Howell-Smith, and Sashi Balakrishnan. 2021. "Effect of Dispersant Concentration with Friction Modifiers and Anti-wear Additives on the Tribofilm Composition and Boundary Friction". Loughborough University. https://hdl.handle.net/2134/13603112.v1. 


\section{American Society of Mechanical Engineers}

SETTING THE STANDARD

\section{ASME Accepted Manuscript Repository}

\section{Institutional Repository Cover Sheet}

ASME Paper Title: Effect of Dispersant Concentration With Friction Modifiers and Anti-Wear Additives on the

Tribofilm Composition and Boundary Friction

Authors: $\quad$ J. Umer, N.J. Morris, R. Rahmani, H. Rahnejat, S. Howell-Smith, S. Balakrishnan

ASME Journal Title: Journal of Tribology

Volume/Issue 143(11)

Date of Publication (VOR* Online) February 23, 2021

https://asmedigitalcollection.asme.org/tribology/article/143/11/111901/1097078/Eff

ASME Digital Collection URL: Concentration-With-Friction

DOI: $\quad$ https://doi.org/10.1115/1.4050017

*VOR (version of record) 


\title{
Effect of dispersant concentration with friction modifiers and anti-wear additives on the tribofilm composition and boundary friction
}

\author{
J. Umer ${ }^{1+}$, N. J. Morris ${ }^{1 *}$, R. Rahmani ${ }^{1}$, H. Rahnejat ${ }^{1+}$, S. Howell-Smith ${ }^{2}$, S. Balakrishnan ${ }^{3}$ \\ ${ }^{1}$ Wolfson School of Mechanical, Electrical and Manufacturing Engineering, Loughborough \\ University, Leicestershire, UK \\ ${ }^{2}$ Capricorn Automotive Ltd., Basingstoke, UK \\ ${ }^{3}$ Castrol Ltd., BP Technology Centre, Whitchurch Hill, Pangbourne, Berks, UK \\ ${ }^{*}$ Corresponding author: N.J.Morris@,lboro.ac.uk \\ ${ }^{+}$Department of Mechanical Engineering, University of Engineering and Technology, \\ Lahore, 54890, Pakistan \\ ${ }^{++}$now at University of Central Lancashire, UK
}

\begin{abstract}
To extend drain intervals and improve efficiency, new engine oils with increased dispersant concentration and reduced viscosity are required. Low viscosity engine oils can increase the prevalence of boundary friction at low temperature and increase its severity at higher temperatures. As a result, combinations of organic and inorganic friction modifiers (FM) will be used to reduce boundary friction across a range of temperatures, also preventing damage to vehicle catalysts. This paper presents an experimental case study of such new generation of fully-formulated engine lubricants with varying concentrations of polyisobutylene succinimide dispersant, organic and inorganic FM. Representative conditions pertaining to those encountered at the top dead centre reversal of the piston compression ring-cylinder liner contact are created, and the generated friction measured through use of a sliding-strip tribometry. Subsequently, X-Ray Photoelectron Spectroscopy (XPS) is used to determine the composition of the formed surface tribofilms in order to explain the observed frictional characteristics. The key interactions and frictional behaviour of the dispersant and friction modifiers are highlighted across a range of operating temperatures.
\end{abstract}

Keywords: Friction; Dispersants; Tribofilm ; Friction Modifiers

\section{Notations:}

Disp Dispersant

FM Friction Modifier

IC Internal Combustion

IFM Inorganic Friction Modifier

KV Kinematic Viscosity 


$\begin{array}{ll}\text { OFM } & \text { Organic Friction Modifier } \\ \text { MoDTC } & \text { Molybdenum Dithiocarbamates } \\ \text { MoS2 } & \text { Molybdenum Disulphide } \\ \text { MTM } & \text { Mini Traction Machine } \\ \text { PIBS } & \text { PolyIsoButylene Succinimide } \\ \text { RMS } & \text { Root Mean Square } \\ \text { SLIM } & \text { Space Layer Imaging Method } \\ S_{k} & \text { Surface core height } \\ S_{p k} & \text { Surface peak height } \\ S_{q} & \text { Surface root mean square roughness } \\ S_{v k} & \text { Surface valley depth } \\ \text { TBN } & \text { Total Base Number } \\ \text { XPS } & \text { X-ray Photoelectron Spectroscope } \\ \text { ZDDP } & \text { Zinc Dialkyldithiphosphate }\end{array}$

\section{Introduction}

Improving energy efficiency of internal combustion (IC) engines is a key intermediate term challenge for the automotive industry. In the case of commercial light-duty vehicles, thermodynamic and frictional losses can account for $62 \%$ and $16.5 \%$ of the expended fuel energy, respectively [1]. The frictional losses can potentially rise to $21.5 \%$ of the fuel consumption under urban driving conditions [2]. To some extent the same losses also apply to IC engines used as a part of hybrid powertrains or as IC range extenders.

The primary function of lubricants is to reduce friction and aid cooling, as well as protect the contacting surfaces in relative motion through formation of a tribofilm [3-5]. Under harsher operating conditions, experienced in downsized IC engines and with the continually reducing lubricant viscosity grades (to mitigate viscous friction), more of the contact conjunctions tend to operate in mixed and boundary regimes of lubrication. Therefore, the role of lubricant additives, which are responsible for the formation of tribofilms, has become more prominent $[6,7]$. Thus, the optimisation of tribological contacts for minimisation of friction and power loss, whilst enhancing system durability can lead to significant economic gains, as well as environmental protection through reduced emissions [8-10].

The piston-cylinder system is the primary contributor to frictional power losses in IC engines, accounting for $45 \%$ of all such losses. Therefore, there is significant potential for improvement. 
Considering the number of IC engine-operated or hybrid propulsion vehicles worldwide, improving the frictional performance can ultimately reduce the adverse environmental emissions [8]. It has been shown by many studies that the reciprocating motion of the piston results in the cessation of lubricant entrainment at piston dead centre reversals, where mixed and boundary regimes of lubrication are prevalent with contact load intensity in the range of $502-952 \mathrm{~N} / \mathrm{m}[5,11-13]$. Therefore, the role of lubricant additives is particularly important in the formation of interfacial protective tribofilms in such regions.

There have been numerous studies conducted to further understand the role of various lubricant additives and their synergistic or antagonistic interactions with each other and with the contacting surfaces [14-18]. Inoue and Watanabe [14] studied the complex interactions of lubricant additives based on surface chemistry. The interactions between different metallic detergents with anti-wear zinc dithiophosphate with succinimide dispersants were investigated [14]. It was noted that the process of tribofilm formation involved the adsorption or bonding to the metallic surfaces, polar molecule solubilisation and decomposition. They determined that the detergents do not have any interaction with zinc dithiophosphate, but ashless dispersants have strong interactions with it. Barcroft and Park [15] investigated the effect of temperature, concentration and interaction of zinc dialkyldithiphosphates with various dispersants. They determined that dispersants lower the extent of ZDDP tribofilm formation without influencing its composition. Zhang et al [16] studied the antagonistic effect of succinimide dispersants on ZDDP tribofilm formation. They used a Mini Traction Machine (MTM) with a Space Layer Imaging Method (SLIM) to measure the growth of a ZDDP tribofilm for varying concentrations of dispersants. They measured a 40-60\% reduction in the ZDDP tribofilm thickness when increasing the concentration of dispersants from 0.0167-0.15 wt\%. The ZDDP tribofilm removal rate also increased with the concentration of dispersants. It was also noted that succinimide dispersants form a thin tribofilm of $2 \mathrm{~nm}$ thickness on an AISI 52100 steel substrate. Martin et al [17] investigated the role of nitrogen in tribochemical reactions between a polyisobutylene succinimide (PIBS) dispersant and zinc dithiophosphate under boundary regime lubrication. They formed tribofilms on an AISI 52100 steel substrate with surface roughness of $0.02 \mu \mathrm{m}(\mathrm{Ra})$ using a reciprocating friction tester operating at $60^{\circ} \mathrm{C}$ surface temperature and in the presence of a dispersant with $1 \mathrm{wt} \%$ concentration. The dispersant and the formed anti-wear tribofilm were chemisorbed onto the surface, containing a higher concentration of nitrogen and carbon and a lower concentration of phosphorus and zinc in comparison with the lubricant sample in which an anti-wear was used in the absence of any dispersant. Gallopoulos and Murphy [18] investigated the interaction of dispersants with zinc dialkylphosphorodithioate. They also determined a strong chemical interaction of a variety of dispersants including Poly Amino Mono Alkenyl Succinimide (PAMAS), Basic Barium Dinoyl Naphthalene Sulfonate (BBDNS) and Barium Thiophosphate (BTP) with zinc dialkylphosphorodithioate.

An area of investigation has been the interaction of ZDDP and calcium sulphonate detergents [19-22]. Kapsa et al [19] studied the formation of a ZDDP film and its anti-wear properties in combination with a neutral detergent, as well as in the presence of calcium sulphonate used as an over-based agent. Calcium sulphonate is a widely used detergent in engine oils with a high 
Total Base Number (TBN). The composition of the formed tribofilm was shown to be quite different with the additional interactions caused by the over-basing agent. Similar results were shown by Kasrai et al [20] for a larger variety of ZDDP and sulphonate ratios. A tribofilm was generated using a reciprocating Plint wear tester on an AISI 52100 steel surface. The tribofilm was formed at $100^{\circ} \mathrm{C}$ with an applied contact load of $225 \mathrm{~N}$, sliding reciprocating speed of $25 \mathrm{~Hz}$ and for a test duration of an hour. They showed that the addition of the detergent additive had an adverse effect on the wear performance of ZDDP. Najman et al [21] studied interaction of ashless thiophosphate anti-wear additives with the neutral and over-based calcium sulphonates. The over-based calcium sulphonates increased the capacity of detergents to neutralise the acidic products formed due to oxidation and combustion. The tribofilms of these additives were generated using a high frequency wear tester with a pin-on-flat AISI 52100 steel plate. The tribofilm was formed at the surface temperature of $100^{\circ} \mathrm{C}, 220 \mathrm{~N}$ applied load, scanning frequency of $25 \mathrm{~Hz}$, stroke length $7 \mathrm{~mm}$ and for a duration of an hour. They used X-ray Photoelectron Spectroscopy (XPS), Energy Dispersive X-ray (EDX) analysis and X-ray Absorptions Near Edge Structure (XANES) spectroscopy techniques to characterise the elemental composition of the formed tribofilms. They found that the wear resistance of the tribofilm changes insignificantly by adding neutral calcium sulfonate, but substantially with an over-based calcium sulphonates.

Friction modifiers (FM) are important additives for reducing friction, particularly in boundary or mixed regimes of lubrication [22-24]. Friction modifiers can be categorised as organic or inorganic [25]. The inorganic friction modifiers are organomolybdenum-type compounds which break down into low shear strength compounds, such as molybdenum disulphide $\left(\mathrm{MoS}_{2}\right)$ in sliding contacts and effectively reduce friction [26-28]. On the other hand, the organic friction modifiers are physisorbed to the sliding surfaces, mainly through the short-range van der Waals' interactions between the lubricant molecules and the adjacent surface. These form monolayers of molecules on the surface and prevent direct contact of mating surfaces, thus reducing friction $[25,29]$. An effective reduction in friction in the presence of friction modifiers requires critical concentration and temperature to activate them in shear [30].

A tribofilm can be generated on a surface attaining the required activation energy of the surface-active additives present in the lubricant at microscale contact conditions through tribometry [5] or at nanoscale contacts using an AFM operating in lateral force mode [5, 31]. Miklozic et al. [32] generated a MoDTC derived tribofilm using a high frequency reciprocating rig and characterised it for elemental composition through use of Raman spectroscopy and at nanoscale by using AFM. They found that friction reducing characteristics of a molybdenum disulphide film, formed on the surface depended on the concentration of MoDTC in the solution and on the operating temperature. The experimental results showed a reduction in friction at a temperature higher than $70^{\circ} \mathrm{C}$ with a concentration of $0.2 \mathrm{wt} \% \mathrm{MoDTC}$ additive in the base oil.

Inorganic friction modifiers have been widely used since 1960s in commercial lubricants $[33,34]$. Organic friction modifiers are deemed as advantageous for use in commercial lubricants $[35,36]$. However, the synergism of ZDDP in facilitating the functionalisation of MoDTC by the formation of low shear compound $\mathrm{MoS}_{2}$ is also reported in the literature [37- 
39]. Muraki et al [37] investigated the synergistic effect of MoDTC and ZDDP for slidingrolling contact conditions. They used a two-roller tribometer to characterise and generate tribofilm on AISI 52100 bearing steel using BO, BO with MoDTC, BO with ZDDP, and BO with a combination of ZDDP and MoDTC. The tribofilm was then elementally characterised using XPS. They found that the presence of ZDDP helps in the decomposition of MoDTC to low friction $\mathrm{MoS}_{2}$ and hence, reduction of friction. Kasrai et al [38] studied antiwear tribofilm using X-ray absorption spectroscopy formed by a combination of MoDTC and ZDDP. They used MCT-10 BO and MoDTC and ZDDP additives to generate tribofilm on a 52100 steel surface. They found that the presence of MoDTC with ZDDP offers comparable wear resistance characteristic to the lubricant samples when ZDDP used alone in BO. They also found that the presence of sulphur in tribofilm is in the form of $\mathrm{MoS}_{2}$-like species and sulphate on the surface for lubricant sample containing MoDTC alone. However, the presence of ZDDP along with MoDTC resulted in higher contents of $\mathrm{MoS}_{2}$-like species than sulphate in the tribofilm. Miklozic et al [39] investigated the performance of tribofilm generated by ZDDP and friction modifiers. They used an MTM and high-frequency reciprocating rig to generate and characterise tribofilm on AISI 52100 steel surface using group II mineral oil and ZDDP and a combination of organic and inorganic friction modifiers. They found that the friction reducing property of OFM depends on the nature of compounds, i.e., amide and amine offers less friction on the ZDDP tribofilm, and fatty acid based OFM was able to reduce friction more effectively on steel surface than ZDDP.

One way to improve the performance of organic FMs is through use of a mixture of organic and inorganic FMs. Lundgren et al [33] studied the improvement in frictional performance of organic friction modifiers by addition of a small amount of inorganic friction modifiers. They used MTM at $100^{\circ} \mathrm{C}$ with a slide-roll ratio of $50 \%$ and an applied load of $20 \mathrm{~N}$ on an AISI 52100 bearing steel surface in order to evaluate the frictional performance of the contact. The lubricant samples used were base oil along with zinc dialkyldithophosphate and an organic friction modifier, including primary fatty amine, diamine and triamines. They observed that diamine and triamine can improve the frictional performance when used with MoDTC, whereas primary fatty amine did not. They concluded that primary fatty amine restricts the low shear strength $\mathrm{MoS}_{2}$ sheets forming on the surface. Rounds [40] investigated the effect of organic friction modifiers, zinc dialkyldithiophosphate anti-wear, metallic detergent and succinimide dispersant on frictional performance in a 4-ball friction tester at different loads and at the temperature of $93^{\circ} \mathrm{C}$ for a 52100 steel surface. It was observed that a higher quantity (e.g. 3\%) of a dispersant has a significant detrimental effect on the anti-wear performance, whereas lower concentrations (e.g. 1\%) do not have a negative effect except at higher contact loads. Therefore, additives used in a base oil play an important role in frictional and wear characteristics of contiguous surfaces. The additives in a base oil have complex synergistic and antagonistic interactions with each other [41]. It is clearly important to advance the fundamental understanding of the interactions of important lubricant additives in contacts [41, 42]. In addition, a recent investigation of the interaction of anti-wear, IFM, dispersants and ionic fluid additives has been conducted in [43]. The results showed significant synergistic and antagonistic interactions, in which the ionic fluid chemistry plays a critical role. 
Modern lubricants are expected to reduce frictional losses across extended drain intervals without adversely interacting with catalysts and particulate filters. To increase drain intervals dispersant concentrations will inevitably have to be increased. However, to avoid undue issues with catalyst and particulate filters it is not desirable to continually increase IFM concentrations [33]. One solution is to introduce OFM, however the introduction of any new additives to an already highly complex fluid needs careful consideration and rigours testing to prevent unwanted tribological behaviour. This paper presents a case study demonstrating the mutual interactions in lubricant formulations that contains high dispersant concentrations and varying IFM (MoDTC) and OFM (Amide) combinations. The experimental case study presented in this paper investigates the frictional behaviour of candidate lubricants using conditions representative of piston ring-cylinder system (pressure, shear, and surface temperature) using a precision sliding strip tribometer. The composition of various generated tribofilms is ascertained through X-ray Photoelectron Spectroscopy and related to measured friction, as well as the evolving changes in surface topography.

\section{Experimental Procedure}

The experimental procedure investigates the frictional characteristics of various lubricant compositions, when used in the contact between a reciprocating sliding strip, loaded against a flat surface (Figure 1 and 2). The sample surface is made of M2 steel alloy, whilst the sliding strip is made of nitrided hardened stainless steel 440B. The triobmetric tests involved sliding the nitride hardened sliding-strip on a softer flat M2 steel alloy. The contact load used for the analysis was $24.85 \mathrm{~N}$ that gives a calculated maximum of Hertzian contact pressure of 33.8 $\mathrm{MPa}$, which is the typical contact pressure for a piston ring and cylinder liner conjunction (although not within Hertzian condition) $[6,44]$. It is important to note that the asperity contact pressure would be higher than the Hertzian. The contact geometry is representative of a typical piston compression ring, parabolic along the sliding direction and conformal perpendicular to the direction of sliding. The sliding strip (4) represents an unwrapped piston top compression ring, sliding on a flat sample surface (5), analogous to the surface of a cylinder liner [5, 6, 45]. Gore et al [46] provided more detail for this particular tribometer, showing that the prevailing conditions closely represent piston ring reversal at the top dead centre of a high-performance motocross motorbike IC engine, when in transition from the compression to the power stroke. The conditions in the stated transition zone represent mixed and boundary regimes of lubrication as noted by Leighton et al [47], where the contact conditions are dominated by the presence of a generated tribofilm. A schematic representation of the sliding strip profile contacting a flat specimen is shown in Figure 1.

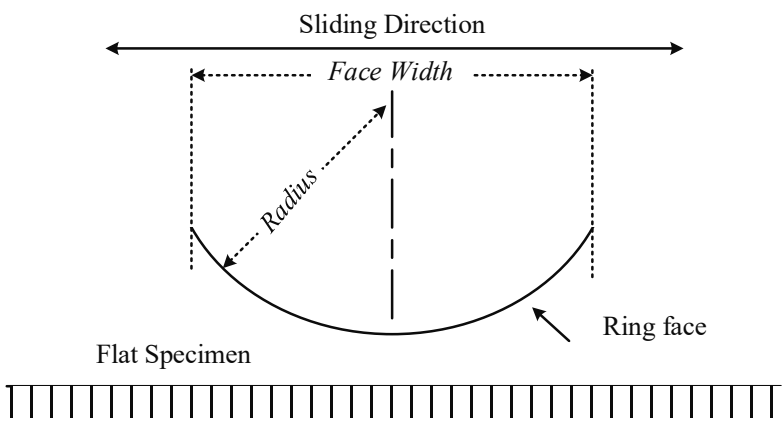


Figure 1: Schematic representation of sliding strip profile contacting a flat specimen

Contact load (8) is applied onto the sliding strip which reciprocates through a precision backlash free leadscrew (2) by an electric motor (1) with a pre-set sliding velocity variation. Lubricant is supplied onto the flat sample surface at the interface with the sliding strip. The generated friction as the result of sliding causes inertial dynamics of the floating plate (3). Therefore, friction is measured directly using a pair of precision piezoelectric sensors (6) mounted at the extremities of the plate's travel. The sliding distance is also measured through use of an encoder (7), shown in Figure 2. A force transduction amplifier (10) is used to amplify the signals of the piezoelectric sensors. The motor is controlled through a controller (9) and heat is supplied to the sample through a transformer (12) and a heater controller (11).

A cleaning procedure is used (section 2.3). Subsequent measurements include topographic measurements of the surface through an Alicona infinite focus microscope (section 2.4) and surface elemental composition using X-ray Photoelectron Spectroscopy (XPS). The characteristics of surface and any potentially generated tribofilm in a nominally dry state (posttribotest) are then compared with the same measurements conducted before tribometry (i.e. pre-tribotest: virgin surface).

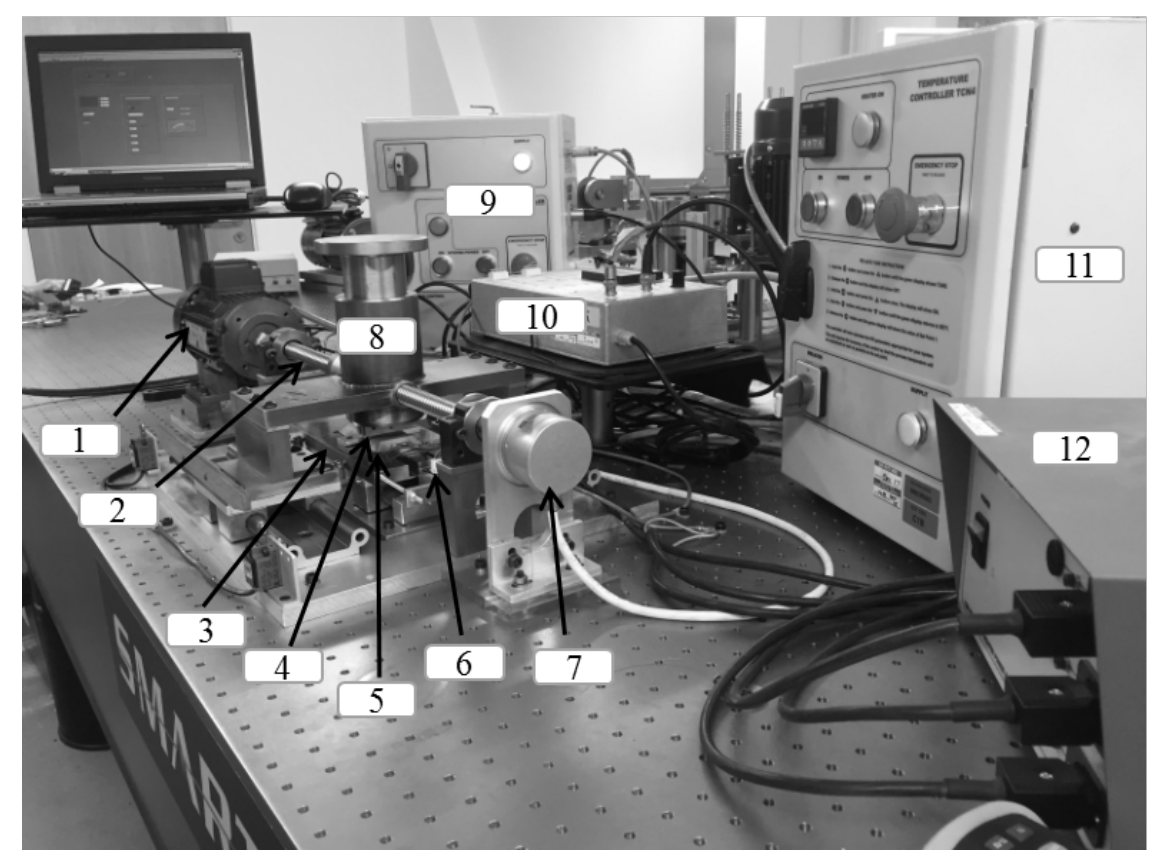

1. Electric motor

2. Lead screw

3. Floating plate

4. $\quad$ Sliding strip

5. Flat sample

6. Piezoelectric sensor

7. Encoder

8. Applied load

9. Motor controller

10. Force transducer amplifier

11. Heater controller

12. Transformer

Figure 2: Sliding strip tribometer

\section{1- Lubricant Samples}

The lubricant samples used in the current study are listed in Table 1. Group III base oils were used to formulate the candidate lubricants. Viscosity variation between candidate lubricants was minimised to reduce differences in viscous friction. In Table 1, IFM denotes a molybdenum-based dithiocarbamates inorganic friction modifier and OFM is an amide organic friction modifier. The description of additives used in lubricant samples is provided in Table 2 . 
The dispersant concentrations are selected as 3\% and 9\%, representing short and long drain intervals respectively. A typical short drain interval lubricant would service an engine for approximately $10,000 \mathrm{~km}$ compared to $25,000 \mathrm{~km}$ to $30,000 \mathrm{~km}$ for a typical long drain interval lubricant. The lubricant samples $\mathrm{A}$ and $\mathrm{E}$ have $3 \%$ and $9 \%$ by weight dispersant treat rates respectively without any friction modifiers. The lubricants $\mathrm{B}$ and $\mathrm{F}$ contain inorganic friction modifiers and $3 \%$ and $9 \%$ by weight dispersant treat rates respectively. Lubricants $\mathrm{C}$ and $\mathrm{G}$ have organic friction modifiers with 3\% dispersant and $9 \%$ by weight dispersant concentration respectively. Lubricant sample $\mathrm{D}$ has a mixture of organic and inorganic friction modifiers with $3 \%$ dispersant by weight, whereas lubricant $\mathrm{H}$ has $9 \%$ by weight dispersant and a mixture of organic and inorganic friction modifiers. The viscosity of all lubricant samples is kept the same in order to ensure constant viscous shear contribution for all lubricant samples. Thus, any variations in the total friction can be attributed to boundary interactions, attributable to formed tribofilms in mixed and boundary regimes of lubrication. The lubricants' kinematic viscosity $(\mathrm{KV})$ is measured at $40^{\circ} \mathrm{C}$ and $100^{\circ} \mathrm{C}$ through ASTM D445 [48]. These are provided in Table 1.

Table 1: Lubricant samples

\begin{tabular}{|c|c|c|c|c|c|}
\hline Sample & IFM & OFM & $\begin{array}{c}\text { Dispersant } \\
\text { [wt \%] }\end{array}$ & $\begin{array}{c}\text { Kinematic Viscosity } \\
@ 4^{\circ} \mathrm{C}[\mathrm{cSt}]\end{array}$ & $\begin{array}{r}\text { Kinematic Viscosity } \\
\text { a } 100^{\circ} \mathrm{C}[\mathrm{cSt}]\end{array}$ \\
\hline A & - & - & \multirow{4}{*}{3} & \multirow{8}{*}{$38.3-40.3$} & \multirow{8}{*}{$7.48-7.55$} \\
\hline B & $\sqrt{ }$ & - & & & \\
\hline $\mathrm{C}$ & - & $\checkmark$ & & & \\
\hline $\mathrm{D}$ & $\checkmark$ & $\checkmark$ & & & \\
\hline $\mathrm{E}$ & - & - & \multirow{4}{*}{9} & & \\
\hline $\mathrm{F}$ & $\checkmark$ & - & & & \\
\hline $\mathrm{G}$ & - & $\checkmark$ & & & \\
\hline $\mathrm{H}$ & $\checkmark$ & $\checkmark$ & & & \\
\hline
\end{tabular}

Table 2: Lubricant additive details

\begin{tabular}{|l|l|}
\hline Lubricant Additives & Description \\
\hline Inorganic Friction Modifier (IFM) & Molybdenum dithiocarbamates $(0.7 \% \mathrm{wt})$ \\
\hline Organic Friction Modifier (OFM) & Amide $(0.2 \% \mathrm{wt})$ \\
\hline Anti-wear & Zinc primary-secondary alkyl dithiophosphate (1\%wt) \\
\hline Viscosity modifier & Olefin copolymer \\
\hline Detergents & $\begin{array}{l}\text { Mixture of low base number synthetic alkyl benzene } \\
\text { calcium sulphonate and Long chain linear alkyl } \\
\text { benzene high base synthetic magnesium sulphonate }\end{array}$ \\
\hline
\end{tabular}




\begin{tabular}{|l|l|}
\hline Dispersant & $\begin{array}{l}\text { high molecular weight; polyisobutylene succinimide } \\
{[2300 \mathrm{Mwt}]}\end{array}$ \\
\hline Antioxidant & $\begin{array}{l}\text { Aminic Octyl/Butyl diphenylamine and Phenolic Ester } \\
(0.5 \% \mathrm{wt})\end{array}$ \\
\hline
\end{tabular}

\section{2- Tribometer tests}

To investigate the frictional behaviour of the lubricants, $1 \mathrm{ml}$ of the test lubricants is applied onto the flat sample surface (5) (Figure 2) and uniformly spread through several reciprocations of the sliding strip. A series of tests are carried out with different lubricant compositions (table 1). For each case a new sample surface and sliding strip are used. Surface topographies of all samples are measured in order to ensure repeatable conditions, thus eliminating the effect of roughness variations on the obtained results.

The operating conditions, chosen for the sliding strip tribometry, are listed in Table 3 . The load per unit lateral length for the strip is in the range 502-952 N/m, representing the contact load conditions for commercial engines $[5,49,50]$. The same is also true of the sliding velocity from the TDC into the power stroke. These are listed in Table 3 as well as other pertinent data. To investigate the performance of lubricant samples at different temperatures, including at high surface temperatures encountered in an IC engine, the sliding strip tribometry is conducted at $20^{\circ} \mathrm{C}, 40^{\circ} \mathrm{C}, 60^{\circ} \mathrm{C}, 80^{\circ} \mathrm{C}, 100^{\circ} \mathrm{C}, 120^{\circ} \mathrm{C}$ and $140^{\circ} \mathrm{C}$. The test samples are heated to a specified temperature. The friction measurements are then conducted after the samples are thermally stabilised at a given temperature. The range of temperatures is selected to replicate the actual engine conditions, from cold start at ambient condition to typical in-cylinder surface temperature as reported by Diaby et al [51]. A total of 70 strokes were conducted at each temperature.

The mid-range temperatures represent transience from cold start-up to the steady state conditions. The samples' temperatures are allowed to stabilise before each measurement is taken. The number of sliding strokes in the tribometric tests is kept constant for all the lubricant variants. Each test is repeated three times, each time with a new sample. The measured data is then averaged.

Table 3: Test conditions and other pertinent data

\begin{tabular}{|l|c|c|}
\hline Parameter & Value & Unit \\
\hline Load per unit length & $777 \pm 9$ & $\mathrm{~N} / \mathrm{m}$ \\
\hline Sliding speed & $(13.0-27.0) \pm 0.2$ & $\mathrm{~mm} / \mathrm{s}$ \\
\hline Stroke length & $14.0 \pm 0.1$ & $\mathrm{~mm}$ \\
\hline Strip width & $1.40 \pm 0.01$ & $\mathrm{~mm}$ \\
\hline Strip length & $32.00 \pm 0.01$ & $\mathrm{~mm}$ \\
\hline Profile crown radius & $32.5 \pm 0.5$ & $\mathrm{~mm}$ \\
\hline
\end{tabular}

\subsection{Cleaning procedure}


A new flat sample and sliding strip are selected and cleaned prior to each test on the tribometer. A thorough cleaning procedure is employed, using petroleum ether 40-60 in an ultrasonic bath for an hour at room temperature. After friction measurements have been conducted hydrocarbon residue is removed with petroleum ether 40-60, leaving only those elements on the surface that are either chemically bonded or adsorbed to the surface, forming a tribofilm. Cleaning of samples is required in order to allow elemental characterisation of any tribofilm through XPS in line with the procedure proposed in [52-55]. After cleaning with petroleum ether 40-60, the samples are dried. Petroleum ether 40-60 evaporates quickly and it is unlikely that a residue would remain on the surface.

\subsection{Topographical measurements}

Surface roughness of the flat samples and the sliding strips are measured using an Alicona G4 infinite focus microscope with $50 \times$ objective lens and a sample area of $286 \times 218 \mu \mathrm{m}^{2}$. The lateral resolution for the objective $50 \times$ lens is $0.64 \mu \mathrm{m}$. The sliding strip has a parabolic profile in the direction of sliding to represent the typical barrel-shaped (parabolic) piston top compression ring contact face curvature. The sliding strip face profile was measured using a $10 \times$ objective lens providing a scanning area of $1429 \times 1088 \mu \mathrm{m}^{2}$ with a lateral resolution of $1.76 \mu \mathrm{m}$. To postprocess the measured topography, the acquired data is levelled through fitting a plane-rotation function and remove any tilt of the sample. The overall form is also removed from the measured data using a cut-off length of $80 \mu \mathrm{m}$.

\subsection{Spectroscopic elemental characterisation of generated tribofilms}

X-ray photoelectron spectroscopy is used to analyse the elemental composition of the flat sample surface before and after the reciprocating friction tests. The XPS analysis was completed after the final measurement of friction was conducted at $140^{\circ} \mathrm{C}$ to investigate the residual tribofilm formed by the interactions of lubricant additives. A Thermo-scientific KAlpha XPS is employed for analysis of the nominally dry surfaces, excluding any hydrocarbon residue, scanning an area of $30 \mu \mathrm{m}^{2}$. The analysis is carried out using $\mathrm{Al}-\mathrm{K} \alpha$ micro focused monochromator with $1.4 \mathrm{KeV}$ intensity, representing a scanning depth of 2-3 nm. In order to calibrate for the charge correction, the binding energy of adventitious carbon of $248.8 \mathrm{eV}$ is used. The XPS analysis comprises two phases; (i)- a survey to analyse all elements by considering all the binding energies and (ii)- high resolution scans to further explore some of the elements of particular interest. The surveys were conducted using a pass energy of $200 \mathrm{eV}$ with step size of $1 \mathrm{eV}$. Each scan is conducted with the dwell time of $10 \mathrm{~ms}$ and the results are averaged for 10 repeated scans of each sample. The high-resolution scans are completed using pass energy of $50 \mathrm{eV}$ in steps of $0.1 \mathrm{eV}$. The results for the high-resolution scans are averaged for 5 scans, each with a dwell time of $50 \mathrm{~ms}$. The Thermal Avantage data system is used for curve fitting and analysing the peaks. There were three measurements conducted at different locations and subsequently the average concentration was determined for each sample.

The high-resolution scans are curve-fitted to find the content of C-C, C-H, C-O and C=O. The high-resolution scans are conducted after the surveys for Sulphur, Molybdenum, Calcium, Phosphorus, Magnesium, Nitrogen, Zinc, Carbon, Iron and Oxygen atoms. It is important to 
reiterate that the XPS survey and the high-resolution analysis are limited to a probing depth of 2-3 nm. Therefore, the XPS analysis in this study only represents elemental concentrations at the outermost layer of any tribofilm. The quantification of tribofilm is widely conducted through combination of XPS survey and depth analysis to ensure the constituent elements present in the tribofilm layers formed by the competitive action of surface-active lubricant additives. However, the tribometer testing conducted in this study is confined to a limited number of tribometric cycles in order to guard against any significant variation in the topography of sample surfaces. Therefore, the sliding strip tribometry tends to generate a very thin layer of any tribofilm. In addition, the frictional characteristics measured and compared for the various lubricant samples also represent the response of an outer layer of any tribofilm at the stated applied contact load and sliding velocities. For these reasons only a surface scan rather than an etching procedure is pursued in the current study. Consequently, the survey and high-resolution XPS analysis used in this study deemed to be suitable for the comparison of composition of tribofilms formed during such tribometric experiments.

\section{Results and Discussion}

\subsection{Tribofilm characterisation}

The coefficient of friction and a corresponding spectroscopic elemental composition for surfaces serviced by lubricants containing a lower concentration of dispersant ( $3 \%$ in $A$ ) and higher levels of dispersants ( $9 \%$ in E) are shown in Figure 3. The XPS analysis of M2 steel alloy before the tribological tests were conducted resulted in $69.6 \% \mathrm{C}, 25.3 \% \mathrm{O}, 4.6 \% \mathrm{Fe}$ and $0.5 \%$ of Mn. The XPS analysis shows average concentration and standard deviation for three measurements. The coefficient of friction increases with surface temperature due to the formation of a ZDDP-based tribofilm indicated by the Zn2p and P2p elements shown in the XPS results measured after the final friction measurements conducted at $140^{\circ} \mathrm{C}$.
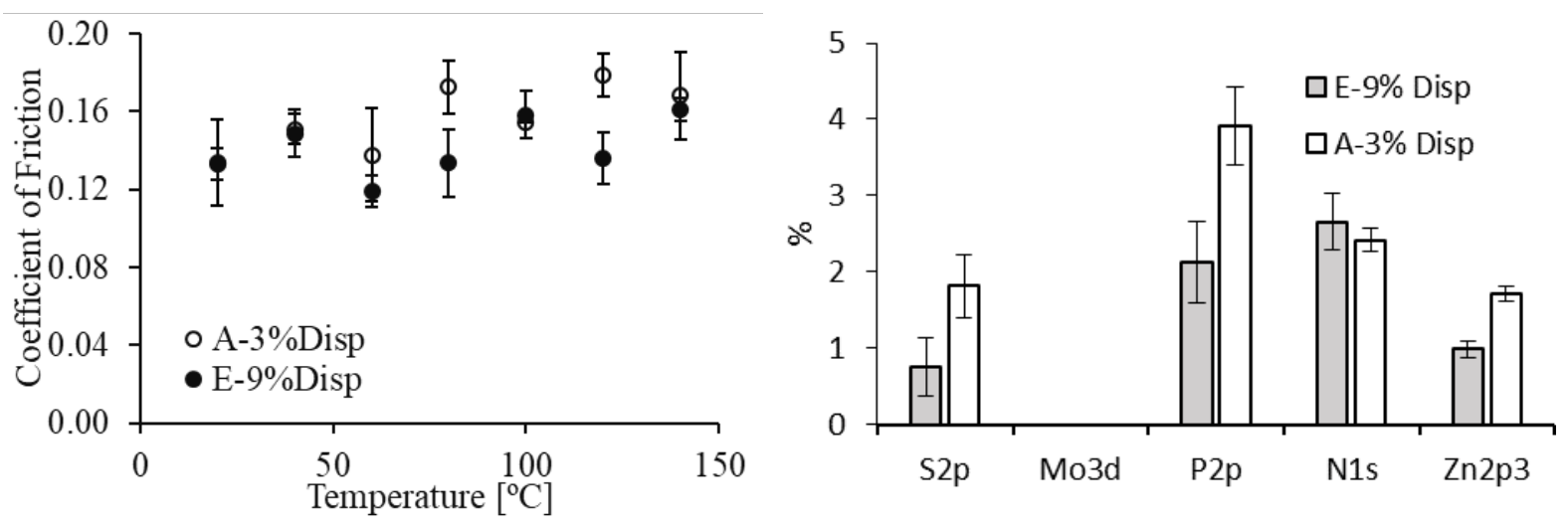

Figure 3: Lubricant samples A: 3\% and E: 9\% dispersant: (left) coefficient of friction vs. temperature, (right) post-friction test XPS analysis

A similar coefficient of friction is obtained for the contact with lubricant A having 3\% dispersant and lubricant $\mathrm{E}$ with 9\% dispersant. The XPS results also indicate the elemental content of the surfaces are similar after the tests are completed with each lubricant. The XPS results also indicate that the elemental components commonly associated with a ZDDP derived anti-wear films ( $\mathrm{Zn}$ and $\mathrm{P}$ ) are more abundant with lower dispersant concentrations in the 
lubricant. The dispersant retards the rate of formation of the anti-wear tribofilm. Similar findings have previously been presented by Zhang and Spikes [16, 56].

The results obtained for lubricant sample B with 3\% dispersant and an inorganic friction modifier (IFM) and lubricant $\mathrm{F}$ with 9\% dispersant and the same IFM are shown in Figure 4. The XPS analysis, which was conducted after the final friction measurements at $140^{\circ} \mathrm{C}$, shows very similar content consistent with the formation of a ZDDP and MoDTC derived tribofilm ( $\mathrm{Zn}, \mathrm{P}, \mathrm{Mo}$ ). The higher level of dispersant is again shown to restrict the concentration of the ZDDP and MoDTC anti-wear film specific element on the surface. The coefficient of friction shown in Figure 4 reduces for temperatures higher than $80^{\circ} \mathrm{C}$ for both lubricant samples. This indicates that shear stress enhanced thermal decomposition of the inorganic friction modifier initiates between $80^{\circ} \mathrm{C}$ and $100^{\circ} \mathrm{C}$. This is in line with the findings of Topolovec Miklozic et al [28].
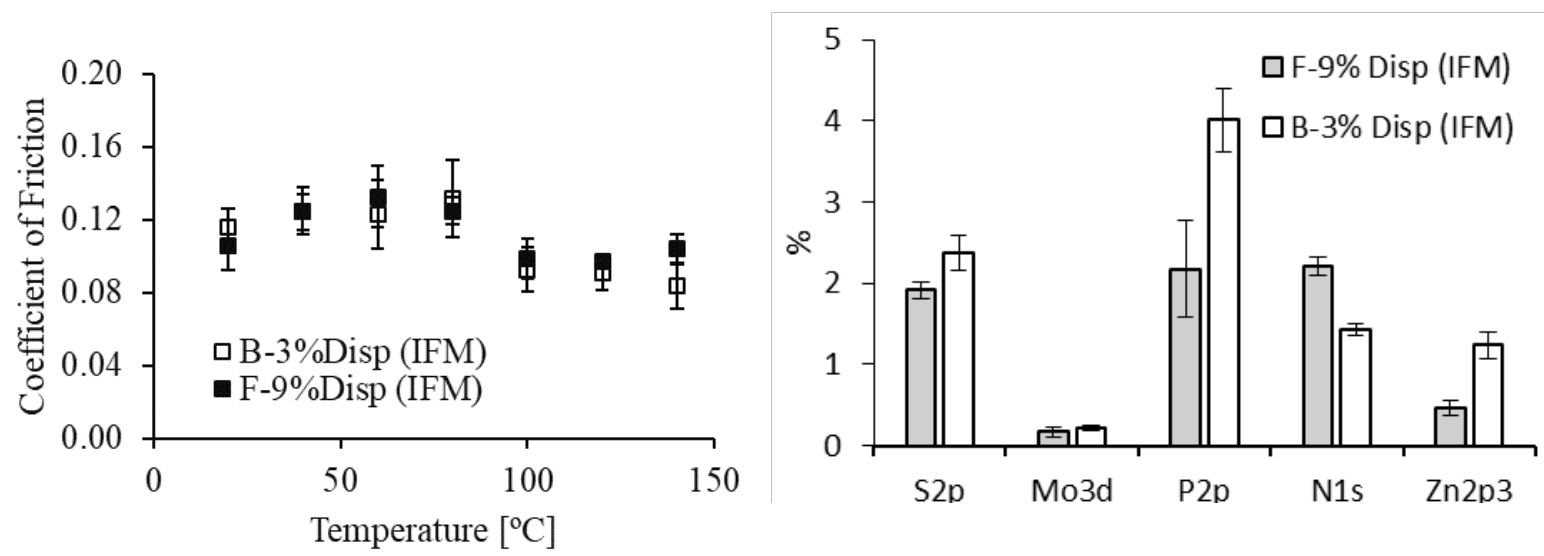

Figure 4: Lubricant samples B with 3\% dispersant with inorganic FM and F-9\% dispersant with the Inorganic FM, (left) coefficient of friction vs. temperature, (right) post-friction test XPS analysis

The results for lubricant samples containing an organic friction modifier with $3 \%$ dispersant (lubricant $\mathrm{C}$ ) and 9\% dispersant (lubricant $\mathrm{G}$ ) are shown in Figure 5. The XPS analysis were conducted after the final friction measurement were conducted at $140^{\circ} \mathrm{C}$ and therefore, includes the contributions at all the investigated temperatures. The lubricant sample $\mathrm{C}$ shows very similar frictional behaviour to the lubricants without OFM shown in Figure 3. Additionally, the anti-wear tribofilm specific components $(\mathrm{Zn} 2 \mathrm{p}, \mathrm{P} 2 \mathrm{p})$ of Lubricant $\mathrm{C}$ are also similar to those shown without friction modifiers in Figure 3.

However, Lubricant sample $\mathrm{G}$ shows a decrease in the coefficient of friction with increasing temperature in comparison with lubricant $\mathrm{C}$ (which shows very similar behaviour to lubricants without friction modifiers; A and E). The anti-wear tribofilm specific components (Zn2p, P2p) shown in Figure 5 and table 4 are noticeably lower for the lubricant $\mathrm{G}$ in comparison to lubricant $\mathrm{C}$. The higher dispersant concentration has been observed to reduce anti-wear film formation in Figure 3 and 4 and published literature [14,16, 39]. The amide OFM has also been shown to also reduce anti-wear film formation in previous studies [14, 39, 57, 58]. The result shown in Figure 5 indicate that the properties of the OFM and the dispersant to restrict ZDDP anti-wear film are complementary. The decrease in friction coefficient produced by lubricant $\mathrm{G}$ results is thought to result from a competitive advantage in film formation afforded to the 
organic friction modifier by dispersant and amide OFM restricting ZDDP antiwear film formation. The results indicate that dispersant concentration can regulate the competition of organic friction modifier and anti-wear additives.
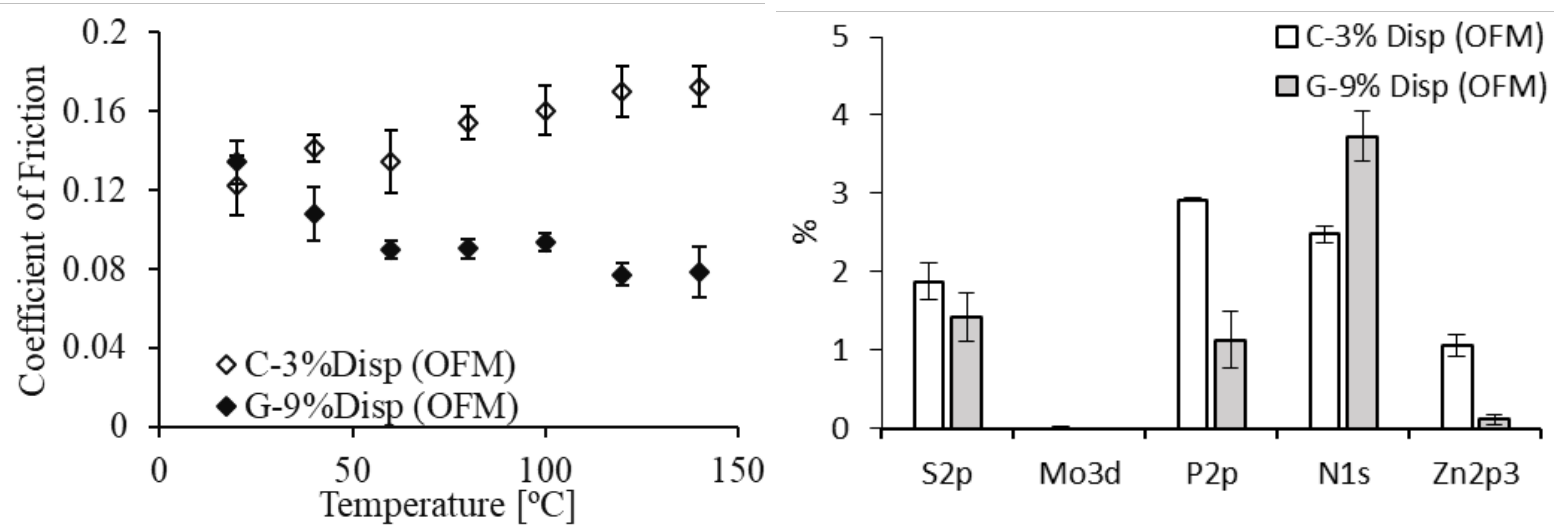

Figure 5: Lubricant samples $C$ with 3\% dispersant with organic FM and G with 9\% dispersant with organic FM: (left) coefficient of friction vs temperature, (right) post-friction test XPS analysis

Figure 6 shows the results for the lubricants H and D which both contain IFM and OFM. In addition, lubricant sample D contains 3\% dispersant and lubricant $\mathrm{H}$ contains $9 \%$ dispersant. Lubricant sample D shows a monotonically decreasing trend in friction with rising temperature. A very similar result, particularly at lower temperatures, is obtained by lubricant $G$ which only contained the OFM. At higher temperatures, the frictional response of D is similar to Lubricants $\mathrm{B}$ and $\mathrm{F}$ which only contained IFM. The XPS data in figure 6 was measured after the final friction measurements were conducted at $140^{\circ} \mathrm{C}$. Therefore, they include contributions from all the preceding friction tests at lower temperatures.

For lubricant $\mathrm{H}$, friction reduction only occurs up to $80^{\circ} \mathrm{C}$, after which the coefficient of friction rises with temperature. Critically, the frictional behaviour shown in Figure 4 indicates that shear stress enhanced thermal decomposition of the IFM occurs after the $80^{\circ} \mathrm{C}$ temperature step. A deterioration in the friction behaviour commences for the contact serviced by lubricant $\mathrm{H}$ after the critical decomposition of the IFM $\left(80^{\circ} \mathrm{C}\right)$ is reached.

A proposed mechanism by which the observed behaviour can be explained is described herewith. It has been shown in Figure 3 that the introduction of OFM in combination with high dispersant concentration significantly restricts ZDDP anti-wear film formation [14, 39, 57, 58]. A reduced concentration of $\mathrm{Zn} 2 \mathrm{p} 3$ and $\mathrm{P} 2 \mathrm{p}$ also occurs for lubricant $\mathrm{H}$ shown in Figure 6. ZDDP has a critical role in formation of anti-wear films however it has also been shown by Morina et al $[59,60]$ and Bouchet et al [61] that ZDDP is key to provide sulphuration of MoDTC derivatives and reduction of $\mathrm{MoO}_{3}$ abrasives [62]. This process promotes the formation of low friction $\mathrm{MoS}_{2}$ tribofilms rather than for example $\mathrm{FeMoO}_{4}, \mathrm{MoDTC}$ derivates associated with deleterious frictional behaviour [63]. The result in Figure 6 can therefore be explained as the amide OFM and high dispersant treat rate prevent the MoDTC-ZDDP synergism and formation of high friction tribofilm. Critically the increase in friction is observed to taken place at the previously observed (figure 4a) stress enhanced thermal decomposition 
temperature of the IFM (MoDTC) of $80-100^{\circ} \mathrm{C}$. Prior to this temperature oil lubricant $\mathrm{H}$ shows the similar behaviour to lubricant G (with only OFM).
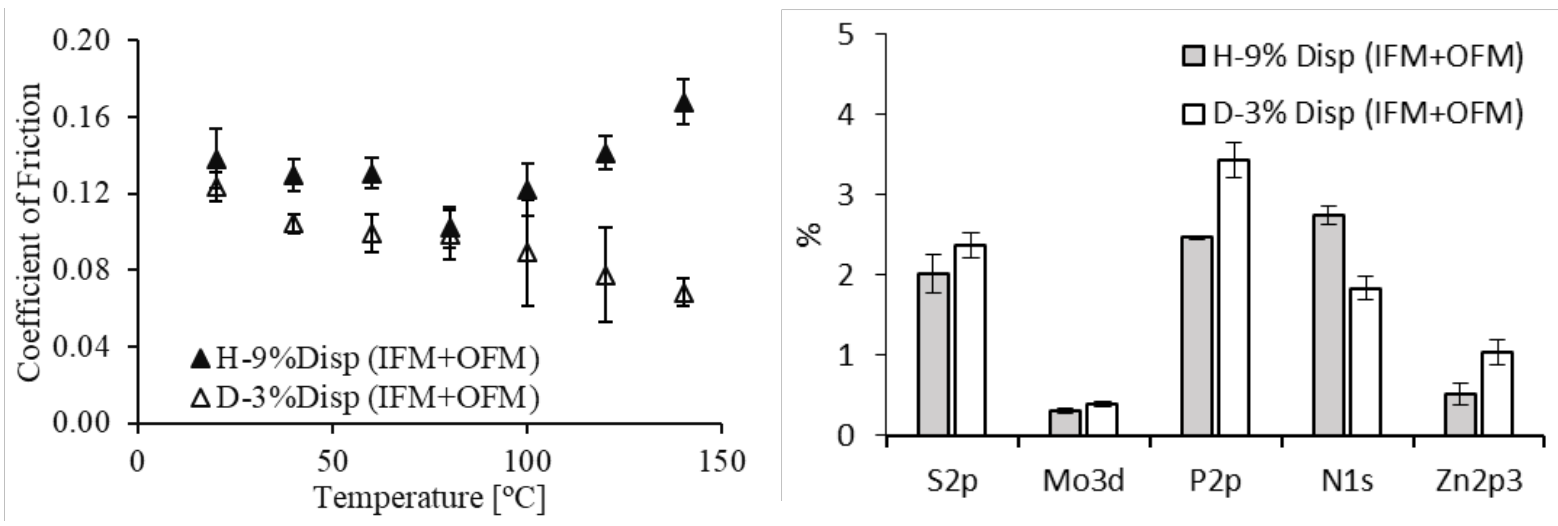

Figure 6: Lubricant samples D with 3\% dispersant with organic and inorganic FM and Lubricant sample $\mathrm{H}$ with $9 \%$ dispersant with organic and inorganic FM: (left) coefficient of friction vs. temperature, (right) friction test XPS analysis

The lubricant samples B with 3\% dispersant and IFM and lubricant D also with 3\% dispersant, but containing both IFM and OFM show similar frictional characteristics above the temperature of $80^{\circ} \mathrm{C}$ (Figure 7). Therefore, it may be summarised that the frictional response of the mixture of OFM and IFM with 3\% dispersant results in the dominant effect of OFM at low temperatures. At higher temperatures very similar behaviour is observed as OFM and IFM in isolation and OFM and IFM in combination with a lower dispersant rate.

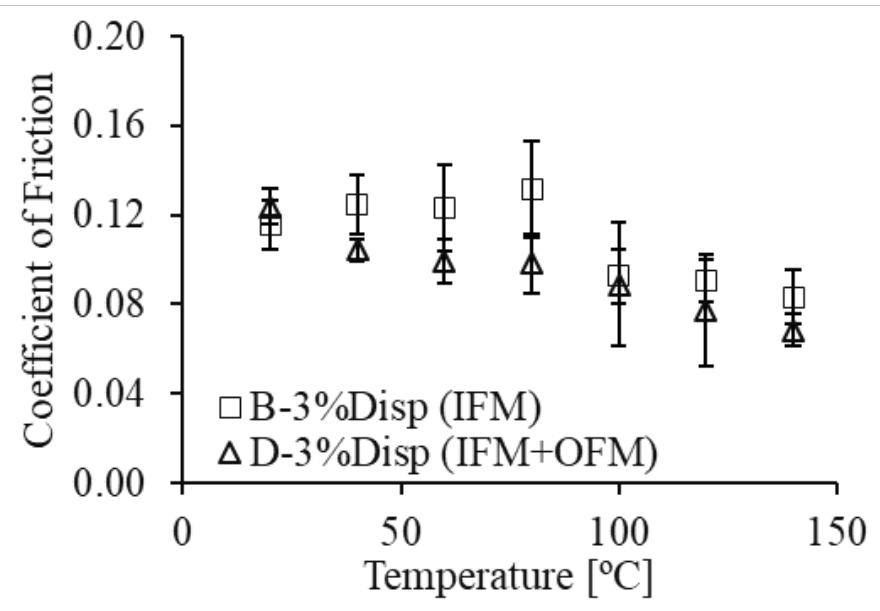

Figure 7: Lubricant samples B with 3\% dispersant and Inorganic friction modifier and Lubricant D with 3\% dispersant and a mixture of organic and inorganic friction modifiers

The effect of friction modifiers, irrespective of the dispersant, is also illustrated in Figure 8 (left) for 3\% dispersant concentration and in Figure 8 (right) for 9\% dispersant concentration. Comparisons show that the lubricant samples with IFM and with combination of IFM and OFM follow a similar trend with respect to temperature. However, the OFM is observed to have an insignificant effect on friction when added with 3\% dispersant concentration. The frictional response of lubricant samples with $9 \%$ dispersant concentration and with $9 \%$ dispersant together with mixture of OFM and IFM are similar at temperatures lower than $80^{\circ} \mathrm{C}$. 

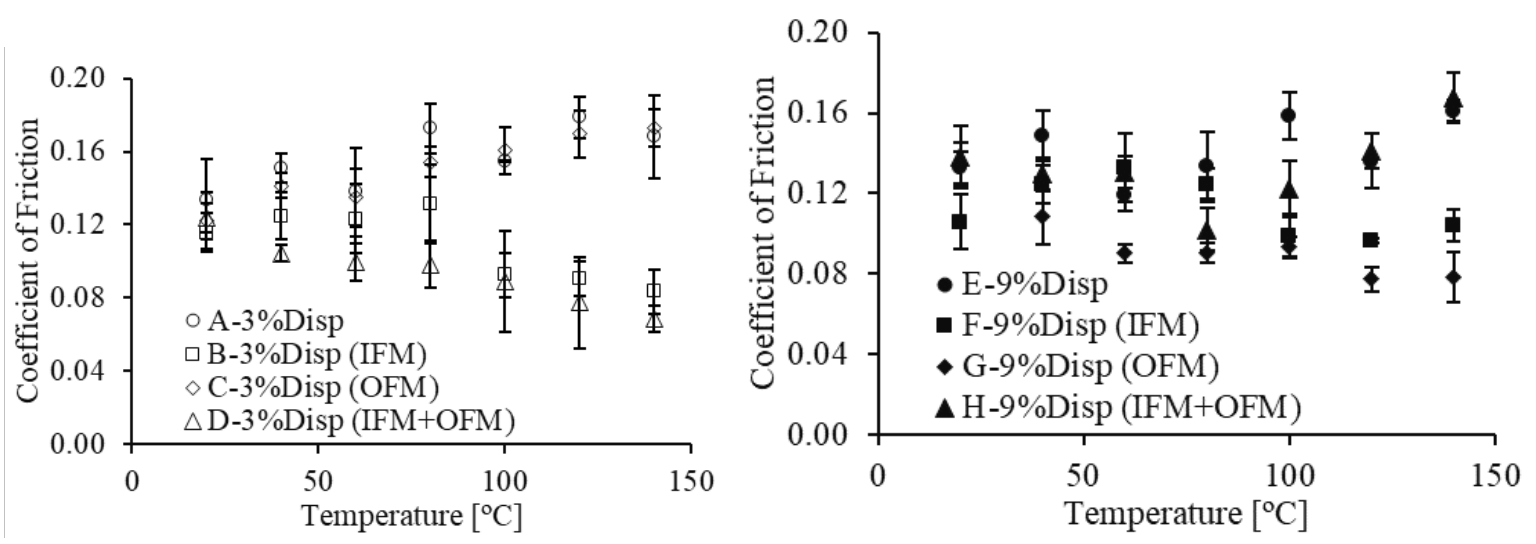

Figure 8: Coefficient of friction for studied lubricant samples with (left) 3\% dispersant and (right) 9\% dispersant

The combined results of high resolution XPS analysis for all the samples along with the associated binding energies are provided in Table 4 . The binding energies shown in the second column align to the values presented for a pure ZDDP by Wei et al [64]. Any shifts in the binding energy may be significant for the identification of by-products of tribo-chemical reactions. However, the current paper's focus is on the spectra described in the table due to the challenges associated with identifying elements with similar oxidation states, when using this method [63].

The XPS results from the high-resolution scan are from a depth of 2-3 $\mathrm{nm}$. The presence of traces of Mo3d indicates the presence of IFM-based tribofilm on the surface. The Mg1s in the tribofilm is an indication of the formation of a detergent-based tribofilm on the surface.

The variation of the average concentration of N1s and C1s for all the lubricant samples show that the cleaning procedure adopted in this study is able to remove lubricant molecules, only leaving the bonded/adsorbed tribofilm contents.

Table 4: High resolution XPS analysis for all the studied lubricant samples

\begin{tabular}{|l|c|c|c|c|c|c|c|c|c|}
\hline $\begin{array}{c}\text { HR-XPS } \\
\text { analysis }\end{array}$ & $\begin{array}{c}\text { Binding } \\
\text { Energy } \\
\text { [eV] } \\
\text { (peak } \\
\text { value) }\end{array}$ & A & B & C & D & E & F & G & H \\
& & & & & & & & & \\
& & & & & & & & \\
\hline $\begin{array}{l}\text { O1s Metal } \\
\text { Oxide }\end{array}$ & $529-530$ & 7.90 & 16.09 & 18.25 & 19.73 & 8.60 & 13.21 & 6.28 & 12.39 \\
\pm 0.89 & \pm 1.43 & \pm 0.29 & \pm 1.19 & \pm 0.87 & \pm 0.81 & \pm 0.82 & \pm 0.95 \\
\hline O1s C-O & 533 & 14.04 & 21.83 & 15.41 & 22.19 & 11.26 & 10.72 & 6.48 & 13.19 \\
& & \pm 1.22 & \pm 2.77 & \pm 1.12 & \pm 0.58 & \pm 0.35 & \pm 1.33 & \pm 0.38 & \pm 1.91 \\
\hline C1s C-C, & 284.8 & 51.08 & 33.37 & 37.65 & 29.10 & 58.15 & 52.63 & 67.06 & 49.78 \\
C-H & & & \pm 2.59 & \pm 1.89 & \pm 1.07 & \pm 0.75 & \pm 3.83 & \pm 1.24 & \pm 2.69 \\
\hline
\end{tabular}




\begin{tabular}{|c|c|c|c|c|c|c|c|c|c|}
\hline C1s C-O & 286 & $\begin{array}{c}7.22 \\
\pm 0.85\end{array}$ & $\begin{array}{c}5.20 \\
\pm 0.14\end{array}$ & $\begin{array}{c}5.93 \\
\pm 0.37\end{array}$ & $\begin{array}{c}4.78 \\
\pm 0.58\end{array}$ & $\begin{array}{c}7.20 \\
0.28 \pm\end{array}$ & $\begin{array}{c}5.11 \\
\pm 0.63\end{array}$ & $\begin{array}{c}6.32 \\
\pm 0.26\end{array}$ & $\begin{array}{c}5.57 \\
\pm 0.37\end{array}$ \\
\hline $\begin{array}{l}\text { C1s } \\
\text { O-C }=\mathrm{O}\end{array}$ & 288.5 & $\begin{array}{c}4.19 \\
\pm 0.46\end{array}$ & $\begin{array}{c}5.04 \\
\pm 0.31\end{array}$ & $\begin{array}{c}4.56 \\
\pm 0.51\end{array}$ & $\begin{array}{c}4.55 \\
\pm 0.25\end{array}$ & $\begin{array}{c}3.98 \\
\pm 0.69\end{array}$ & $\begin{array}{c}3.68 \\
\pm 0.46\end{array}$ & $\begin{array}{c}3.95 \\
0.52 \pm\end{array}$ & $\begin{array}{c}3.97 \\
\pm 0.49\end{array}$ \\
\hline O1s $C=O$ & $\begin{array}{c}531.5- \\
532\end{array}$ & $\begin{array}{c}3.02 \\
\pm 0.39\end{array}$ & $\begin{array}{c}3.35 \\
\pm 0.34\end{array}$ & $\begin{array}{c}3.09 \\
\pm 0.22\end{array}$ & $\begin{array}{c}2.83 \\
\pm 0.31\end{array}$ & $\begin{array}{c}1.93 \\
\pm 0.36\end{array}$ & $\begin{array}{c}2.07 \\
\pm 0.36\end{array}$ & $\begin{array}{c}1.60 \\
\pm 0.05\end{array}$ & $\begin{array}{c}1.60 \\
\pm 0.06\end{array}$ \\
\hline S2p & $\begin{array}{c}159- \\
171.04 \\
(161.5)\end{array}$ & $\begin{array}{c}1.81 \\
\pm 0.42\end{array}$ & $\begin{array}{c}2.37 \\
\pm 0.21\end{array}$ & $\begin{array}{c}1.88 \\
\pm 0.05\end{array}$ & $\begin{array}{c}2.37 \\
\pm 0.16\end{array}$ & $\begin{array}{c}0.75 \\
\pm 0.38\end{array}$ & $\begin{array}{c}1.91 \\
\pm 0.10\end{array}$ & $\begin{array}{c}1.42 \\
\pm 0.30\end{array}$ & $\begin{array}{c}2.02 \\
\pm 0.24\end{array}$ \\
\hline Mo3d & $\begin{array}{c}224-238 \\
(228)\end{array}$ & - & $\begin{array}{c}0.22 \\
\pm 0.03\end{array}$ & - & $\begin{array}{c}0.40 \\
\pm 0.04\end{array}$ & - & $\begin{array}{c}0.17 \\
\pm 0.07\end{array}$ & - & $\begin{array}{c}0.31 \\
\pm 0.03\end{array}$ \\
\hline P2p & $\begin{array}{c}126.25- \\
137.29 \\
(133)\end{array}$ & $\begin{array}{c}3.91 \\
\pm 0.52\end{array}$ & $\begin{array}{c}4.01 \\
\pm 0.39\end{array}$ & $\begin{array}{c}2.92 \\
\pm 0.19\end{array}$ & $\begin{array}{c}3.44 \\
\pm 0.22\end{array}$ & $\begin{array}{c}2.12 \\
\pm 0.52\end{array}$ & $\begin{array}{c}2.17 \\
\pm 0.59\end{array}$ & $\begin{array}{c}1.13 \\
\pm 0.37\end{array}$ & $\begin{array}{c}2.47 \\
\pm 0.03\end{array}$ \\
\hline Mg1s & $\begin{array}{l}1303- \\
1305 \\
(1303)\end{array}$ & - & $\begin{array}{c}0.45 \\
\pm 0.08\end{array}$ & $\begin{array}{c}0.81 \\
\pm 0.18\end{array}$ & $\begin{array}{c}1.01 \\
\pm 0.14\end{array}$ & - & $\begin{array}{c}0.31 \\
\pm 0.16\end{array}$ & $\begin{array}{c}0.03 \\
\pm 0.03\end{array}$ & $\begin{array}{c}0.29 \\
\pm 0.02\end{array}$ \\
\hline N1s & $\begin{array}{c}394-408 \\
(397)\end{array}$ & $\begin{array}{c}2.42 \\
\pm 0.15\end{array}$ & $\begin{array}{c}1.43 \\
\pm 0.07\end{array}$ & $\begin{array}{c}2.48 \\
\pm 0.15\end{array}$ & $\begin{array}{c}1.84 \\
\pm 0.15\end{array}$ & $\begin{array}{c}2.66 \\
\pm 0.38\end{array}$ & $\begin{array}{c}2.21 \\
\pm 0.11\end{array}$ & $\begin{array}{c}3.73 \\
\pm 0.31\end{array}$ & $\begin{array}{c}2.75 \\
\pm 0.11\end{array}$ \\
\hline $\begin{array}{l}\text { Zn2p3 } \\
\text { Oxide }\end{array}$ & $\begin{array}{c}1017- \\
1050 \\
(1022)\end{array}$ & $\begin{array}{c}1.71 \\
\pm 0.11\end{array}$ & $\begin{array}{c}1.24 \\
\pm 0.17\end{array}$ & $\begin{array}{c}1.05 \\
\pm 0.23\end{array}$ & $\begin{array}{c}1.04 \\
\pm 0.15\end{array}$ & $\begin{array}{c}0.99 \\
\pm 0.10\end{array}$ & $\begin{array}{c}0.47 \\
\pm 0.09\end{array}$ & $\begin{array}{c}0.11 \\
\pm 0.06\end{array}$ & $\begin{array}{c}0.51 \\
\pm 0.14\end{array}$ \\
\hline $\begin{array}{l}\text { Fe2p3 } \\
\text { Oxide }\end{array}$ & $\begin{array}{r}703-727 \\
(706.7)\end{array}$ & $\begin{array}{c}2.59 \\
\pm 0.32\end{array}$ & $\begin{array}{c}5.41 \\
\pm 0.67\end{array}$ & $\begin{array}{c}5.86 \\
\pm 0.47\end{array}$ & $\begin{array}{c}6.72 \\
\pm 0.43\end{array}$ & $\begin{array}{c}2.61 \\
\pm 0.19\end{array}$ & $\begin{array}{c}4.02 \\
\pm 0.52\end{array}$ & $\begin{array}{c}1.77 \\
\pm 0.10\end{array}$ & $\begin{array}{c}4.24 \\
\pm 0.46\end{array}$ \\
\hline
\end{tabular}

The combination of adventitious carbon and the organic friction modifier through high resolution scans are shown in Figure 9. Although, there is a likelihood of carbon contamination on samples, it is assumed a similar contamination occurs across all samples. The concentration of $\mathrm{C} 1 \mathrm{~s}$ is always higher in the case of $9 \%$ dispersant content, in line with the results for the XPS survey and similar findings are also shown in literature [17]. In addition, the tribofilm with $9 \%$ dispersant and organic friction modifier (i.e. the lubricant sample $\mathrm{G}$ ) has highest percentage of $\mathrm{C} 1 \mathrm{~s}, \mathrm{C}-\mathrm{C}$, and $\mathrm{C}-\mathrm{H}$ among all the samples. 


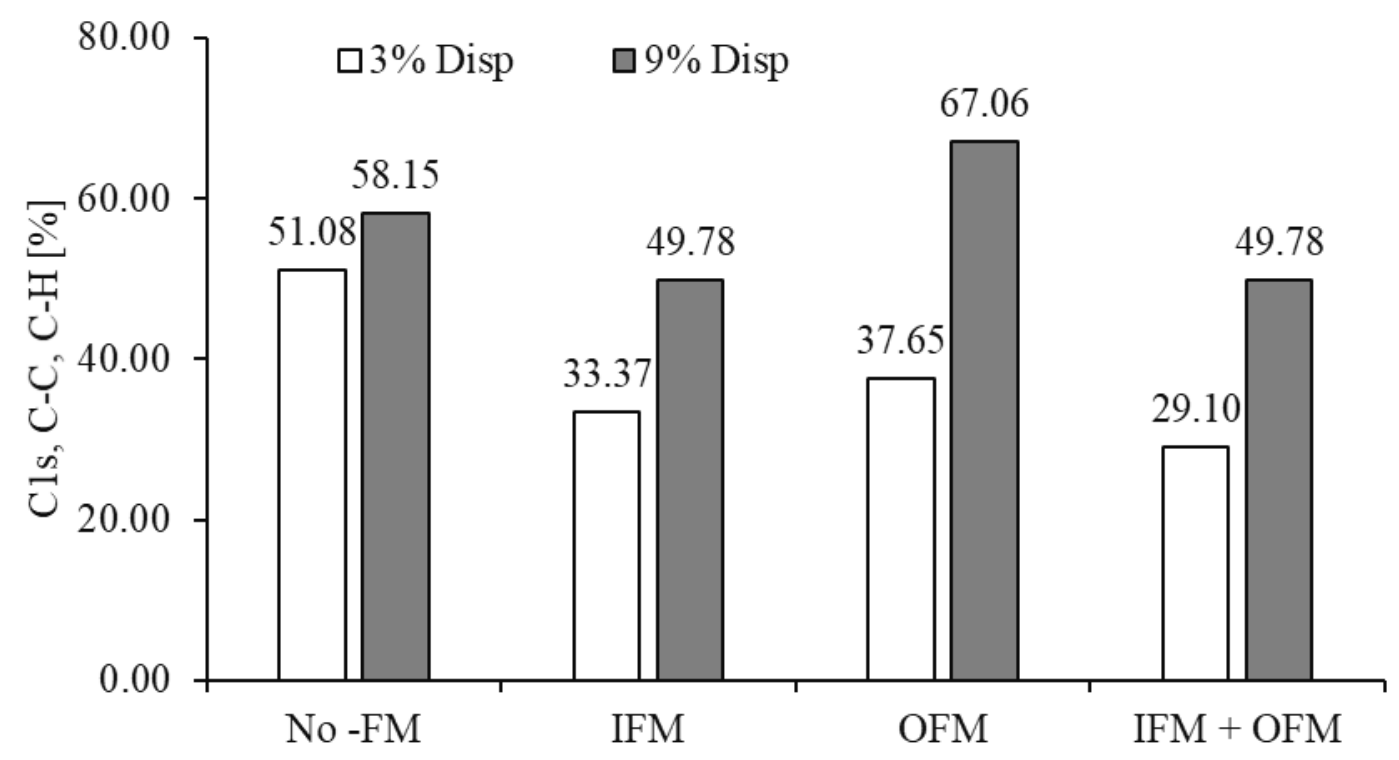

Figure 9: Contribution of adventitious carbon and organic friction modifiers through high-resolution scan for $\mathrm{C} 1 \mathrm{~s}, \mathrm{C}-\mathrm{C}, \mathrm{C}-\mathrm{H}$ with binding energy of $284.8 \mathrm{eV}$

\subsection{Effect of surface roughness}

The average and RMS surface roughness of the sliding strip and flat counter face are measured using focus variation microscopy with a $50 \times$ magnification objective lens providing a field of view of $286 \times 218 \mu \mathrm{m}^{2}$. The results of the measurements are shown in Figures 10 and 11 respectively. The results prior to friction measurements on the tribometer are labelled "pre-test" whereas, the "post-test" is performed after all friction measurements are completed. The average and RMS surface roughness, shown in Figures 10 and 11, decrease for all samples post tribometric testing. The sliding strips are nitride hardened. Therefore, the average and RMS surface roughness show little change. The surface roughness of the flat specimens varies more significantly. This is due to the contact of a hard strip surface (nitride hardened sliding strip) with the softer M2 tool steel, causing running-in wear and bedding-in of flat surfaces. The variation of average and RMS roughness for the sliding strip, is negligible and hence, deemed to be insignificantly in influencing the frictional performance of the lubricant samples as shown in Figure 10 and 11 respectively. The change in measured surface topography is due to the combined effect of tribofilm formation; adsorption and desorption [65] as well as ploughing plastic deformation of asperities on the softer counter face [10]. 

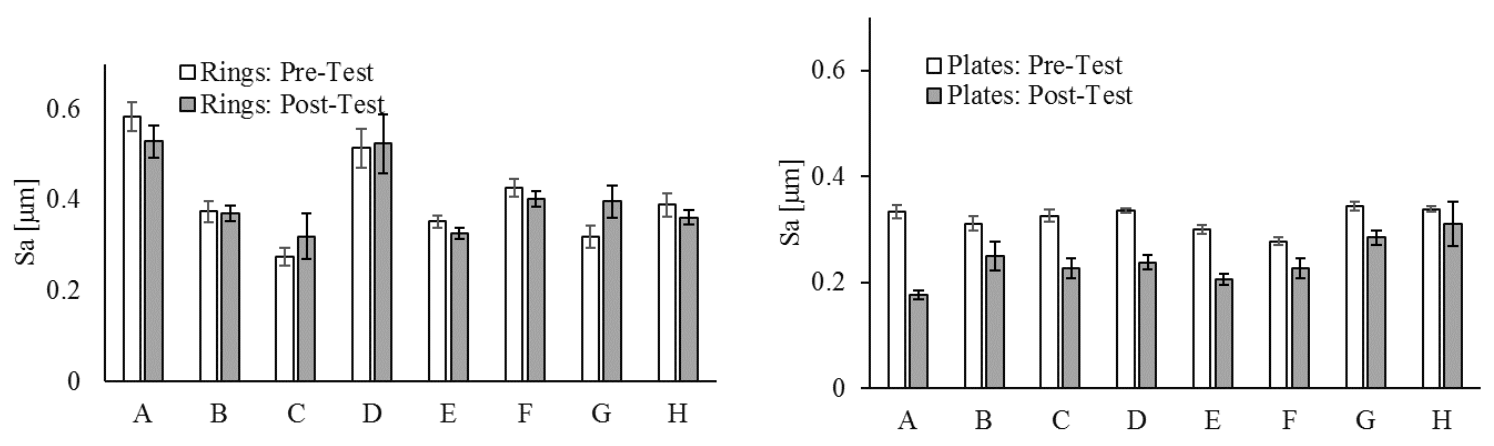

Figure 10: Average surface roughness for the sliding strip (left) and flat specimen (right) pre- and post-tribometry
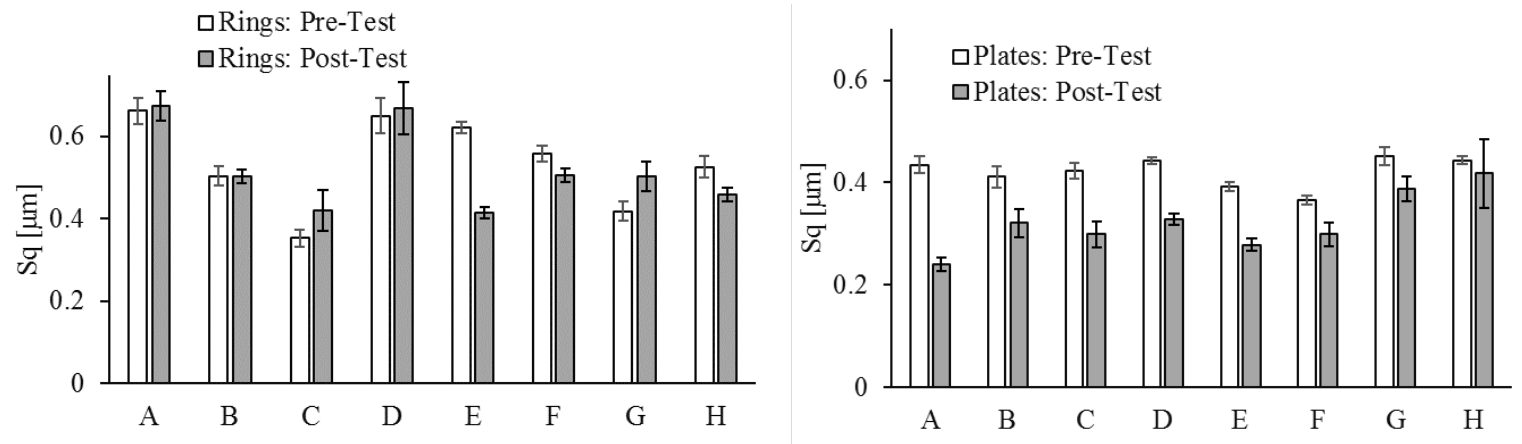

Figure 11: Surface RMS roughness for sliding strip (left) and flat specimen (right) pre- and posttribometry

The surface topography for pre and post friction tests are further analysed by investigating relevant parameters for Abbott Firestone Curve. Therefore, the change in the RMS surface roughness $\left(\Delta S_{q}\right)$ and reduced peak height $\left(\Delta S_{p k}\right)$ are evaluated in order to ascertain the variation in surface topography with growth and composition of any tribofilm:

$\Delta S_{q}=S_{q(\text { Pre }- \text { Tribo })}-S_{q(\text { Post-Tribo })}$

$\Delta S_{p k}=S_{p k(\text { Pre }- \text { Tribo })}-S_{p k(\text { Post-Tribo })}$

The variation in the RMS surface roughness and reduced peak height of flat samples are analysed with the context of the elemental composition of a generated tribofilm (Figure 12). Surfaces such as those used in the current investigation are only in relative sliding motion for a limited period time and as such experience a period of running-in wear. The reduction of the roughness parameters; $S_{q}$ and $S_{p k}$ indicate that all the surfaces undergo some degree of polishing. It can be observed that the surface subjected to the most severe running-in wear (changes in Sq and Spk) also tends to be the one with the highest surface Zinc content. This is due to the formation of nascent surface sites with high flash temperatures and interfacial shear stress in asperity-level ploughing, leading to surface polishing in the running-in period. These conditions suit the formation of tribofilm adsorption including that of ZDDP derivatives. 


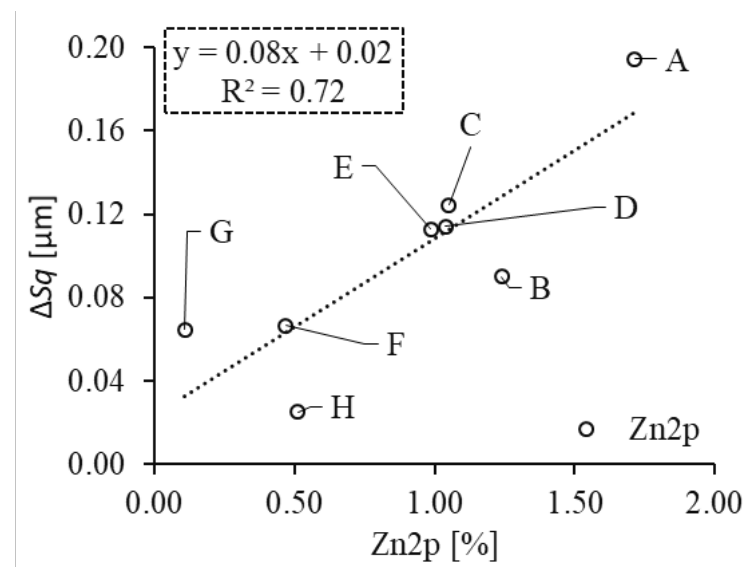

a)

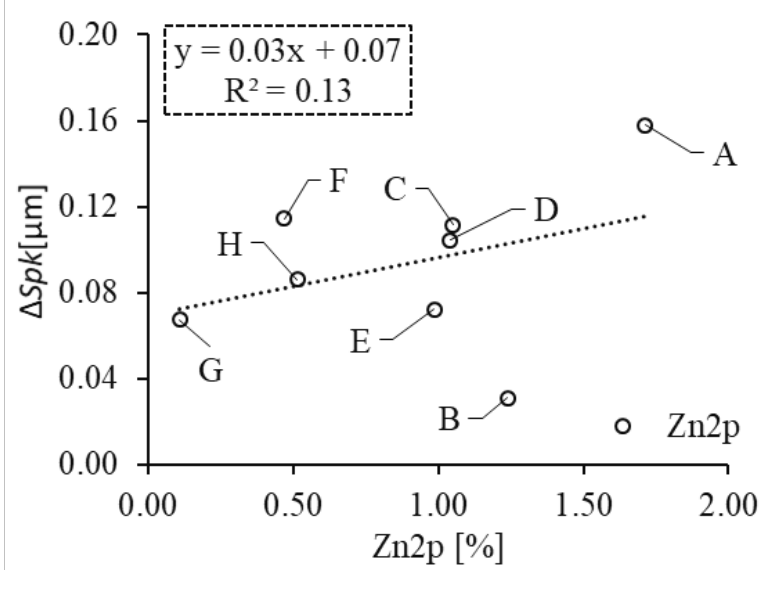

b)

Figure 12: Effect of Zn2p on changes in a) RMS roughness, b) reduced peak height

A direct relation between severity of surface polishing during running-in wear and surface Zinc content can be made. However, no direct relation between severity of running-in wear or Zinc surface content in isolation can be made with friction measurements. Both parameters are involved in generation of boundary friction in a highly complex manner.

\section{4- Concluding remarks}

This experimental case study investigates the interaction of friction modifiers and dispersants in modern engine lubricant formulations. This paper presents an experimental approach through which frictional behaviour can be understood by using surface chemistry analysis and topography measurements. The role of dispersant concentrations in short and long drain oil formulations is observed to affect friction and ultimately the vehicle fuel economy. Specifically, this paper shows:

- Increased dispersant treat rate is observed to restricts ZDDP anti-wear film formation.

- When IFM is used as the sole friction modifier low friction behaviour for both high and low dispersant treat rates are observed.

- The results indicate that dispersant treat rate can regulate the competition of OFM and ZDDP anti-wear additives.

$\circ$ When OFM was combined with a high dispersant treat rate very little anti-wear film was generated and low friction behaviour was observed.

- When OFM was used with a low dispersant treat rate an anti-wear film formed and the OFM did not reduce friction.

- It was observed when OFM and IFM were used together at high temperature friction increased for the high dispersant treat rate and showed low friction behaviour with low dispersant treat rate.

A possible mechanism for these observations is given by combining several well know additive pair synergism/antagonism shown separately in literature. Firstly, it has been shown in this study and by others that dispersants and OFM can interrupt the process of ZDDP film antiwear film formation $[14,16,39,57,58]$. It has also been shown in literature ZDDP has a 
synergistic role in the process of MoDTC forming low friction $\mathrm{MoS}_{2}$ tribofilms [59-62]. The observations of this study indicate that the OFM-ZDDP and Dispersant-ZDDP antagonism can combine to prevent the MoDTC-ZDDP synergism if concentrations of OFM and dispersant are suitably high.

An interesting expansion on the current research would be to examine the state of formed tribofilm at each temperature investigated. In addition, the incorporation of Raman Spectroscopy which has been shown to advantageous for inspection of MoDTC tribofilm in literature would enable confirmation of the proposed ZDDP-MoDTC-dispersant interaction mechanism.

\section{Acknowledgements}

The authors would like to express their gratitude for the financial support of the Engineering and Physical Sciences Research Council (EPSRC) and BP through Centre for Doctoral Training in Embedded Intelligence (CDT-ei EP/L014998/1). The first Author also acknowledges the financial support provided to him by the University of Engineering and Technology Lahore under the faculty development programme to conduct this research at Loughborough University. The authors also acknowledge the use of facilities within the Loughborough Materials Characterisation Centre (LMCC).

\section{References}

[1] Holmberg, K., Andersson, P. and Ali, E., "Global energy consumption due to friction in passenger cars", Tribology International, 2012, 47, pp. 221-234.

[2] Uras, H.M. and Patterson, D.J., "Measurement of Piston and Ring Assembly Friction Instantaneous IMEP Method”, SAE Int., No. 830416, 1983.

[3] Spikes, H., "Friction Modifier Additives", Tribology Letters, 2015, 60 (1), p. 5.

[4] Zhang, J. and Spikes, H., "On the Mechanism of ZDDP Antiwear Film Formation", Tribology Letters, 2016, 63 (2), pp. 24.

[5] Umer, J., Morris, N., Leighton, M., Rahmani, R., Balakrishnan, S. and Rahnejat, H., "Nano and microscale contact characteristics of tribofilms derived from fully formulated engine oil", Tribology International, 2019, 131, pp. 620-630.

[6] Leighton, M., Nicholls, T., De La Cruz, M., Rahmani, R. and Rahnejat, H., "Combined lubricant-surface system perspective: Multi-scale numerical-experimental investigation", Proc. IMechE, Part J: J. Engineering Tribology, 2016, 231(7), pp. 910924.

[7] Forder, M., Umer, J., Morris, N., Rahmani, R., Howell-Smith, S. and Rahnejat, H., "Asperity level frictional interactions of cylinder bore materials and lubricant composition", Proc. IMechE, Part J: J. Engineering Tribology, 2020: :1350650120903928.

[8] King, J., "The King review of low-carbon cars Pt. 1., The potential for CO2 reduction", HMSO, London, 2007. 
[9] Holmberg, K. and Erdemir, A., "Influence of tribology on global energy consumption, costs and emissions", Friction, 2017, 5 (3), pp. 263-284.

[10] Gohar, R. and Rahnejat, H., "Fundamemtals of Tribology", Imperial College Press, London, 2008.

[11] Lenauer, C., Tomastik, C., Wopelka, T. and Jech, M., "Piston ring wear and cylinder liner tribofilm in tribotests with lubricants artificially altered with ethanol combustion products", Tribology International, 2015, 82, pp. 415-422.

[12] Bewsher, S.R., Leighton, M., Mohammadpour, M., Rahnejat, H., Offner, G. and Knaus, O., "Boundary friction characterisation of a used cylinder liner subject to fired engine conditions and surface deposition", Tribology International, 2019, 131, pp. 424-437.

[13] Umer, J., Morris, N., Leighton, M., Rahmani, R., Howell-Smith, S., Wild, R. and Rahnejat, H., "Asperity level tribological investigation of automotive bore material and coatings", Tribology International, 2018, 117, pp. 131-140.

[14] Inoue, K. and Watanabe, H., "Interactions of Engine Oil Additives", Transactions of ASLE, 1983, 26 (2), pp. 189-199.

[15] Barcroft, F.T. and Park, D., "Interactions on heated metal surfaces between zinc dialkyldithiophosphates and other lubricating oil additives", Wear, 1986, 108 (3), pp. 213-234.

[16] Zhang, Yamaguchi, E. and Spikes, H., "The Antagonism between Succinimide Dispersants and a Secondary Zinc Dialkyl Dithiophosphate", Tribology Transactions, 2014, 57 (1), pp. 57-65.

[17] Martin, J., Grossiord, C., Le Mogne, T., Igarashi, J., "Role of nitrogen in tribochemical interaction between Zndtp and succinimide in boundary lubrication", Tribology International, 2000, 33 (7), pp. 453-459.

[18] Gallopoulos, N.E. and Murphy, C.K., "Interactions Between a Zinc Dialkylphosphorodithioate and Lubricating Oil Dispersants", Transactions of ASLE, 1971, 14 (1), pp. 1-7.

[19] Kapsa, P., Martin, J.M., Blanc, C. and Georges, J.M., "Antiwear Mechanism of ZDDP in the Presence of Calcium Sulfonate Detergent", Journal of Tribology, 1981, 103 (4), pp. 486.

[20] Kasrai, M., Fuller, M.S., Bancroft, G.M. and Ryason, P.R., "X-Ray Absorption Study of the Effect of Calcium Sulfonate on Antiwear Film Formation Generated From Neutral and Basic ZDDPs: Part 1-Phosphorus Species", Tribology Transactions, 2003, 46 (4), pp. 534-542.

[21] Najman, M., Kasrai, M., Bancroft, M.G. and Davidson, R., "Combination of ashless antiwear additives with metallic detergents: interactions with neutral and overbased calcium sulfonates", Tribology International, 2006, 39 (4), pp. 342-355. 
[22] Korcek, S., Jensen, R.K., Johnson, M.D. and Sorab, J., "Fuel efficient engine oils, additive interactions, boundary friction, and wear", Tribology Series, 1999, 36, pp. 1324.

[23] Ratoi, M., Niste, V.B., Alghawel, H., Suen, Y.F. and Nelson, K., "The impact of organic friction modifiers on engine oil tribofilms", RSC Advance, 2014, 4 (9), pp. 4278-4285.

[24] Tung, S.C. and McMillan, M.L., "Automotive tribology overview of current advances and challenges for the future", Tribology International, 2004, 37 (7), pp. 517-536.

[25] Tang, Z. and Li, S., "A review of recent developments of friction modifiers for liquid lubricants (2007-present)", Current Opinion in Solid State and Materials Science, 2014, 18 (3), pp. 119-139.

[26] De Barros, M.I., Bouchet, J., Raoult, I., Le Mogne, T., Martin, J.M., Kasrai, M. and Yamada, Y., "Friction reduction by metal sulfides in boundary lubrication studied by XPS and XANES analyses", Wear, 2003, 254 (9), pp. 863-870.

[27] Grossiord, C., Varlot, K., Martin, J.-M., Le Mogne, T., Esnouf, C. and Inoue, K., "MoS2 single sheet lubrication by molybdenum dithiocarbamate", Tribology International, 1998, 31 (12), pp. 737-743.

[28] Miklozic, K.T., Graham, J. and Spikes, H., "Chemical and Physical Analysis of Reaction Films Formed by Molybdenum Dialkyl-Dithiocarbamate Friction Modifier Additive Using Raman and Atomic Force Microscopy", Tribology Letters, 2001, 11 (2), pp. 7181 .

[29] Levine, O. and Zisman, W.A., "Physical Properties of Monolayers Adsorbed at the Solid-Air Interface. I. Friction and Wettability of Aliphatic Polar Compounds and Effect of Halogenation", The Journal of Physical Chemistry, 1957, 61 (8), pp. 1068-1077.

[30] Graham, J., Spikes, H. and Korcek, S., "The Friction Reducing Properties of Molybdenum Dialkyldithiocarbamate Additives: Part I — Factors Influencing Friction Reduction", Tribology Transactions, 2001, 44 (4), pp. 626-636.

[31] Gosvami, N.N., Bares, J.A., Mangolini, F., Konicek, A.R., Yablon, D.G. and Carpick, R.W., "Mechanisms of antiwear tribofilm growth revealed in situ by single-asperity sliding contacts", Science, 2015, 348 (6230), pp. 102-106

[32] Miklozic, K.T., Graham, J. and Spikes, H., "Chemical and physical analysis of reaction films formed by molybdenum dialkyl-dithiocarbamate friction modifier additive using Raman and atomic force microscopy", Tribology Letters, 2001, 11 (2), pp. 71-81.

[33] Lundgren, S.M., Eriksson, K., Rossenaar, B., "Boosting the Friction Performance of Amine Friction Modifiers with MoDTC", SAE International Journal of Fuels and Lubricants, 2015, 8 (1), pp. 2015-01-0684.

[34] Morina, A., Neville, A., Priest, M. and Green, J.H., "ZDDP and MoDTC interactions and their effect on tribological performance - tribofilm characteristics and its evolution", Tribology Letters, 2006, 24 (3), pp. 243-256.

[35] Gandhi, H.S. and Shelef, M., "Effects of sulphur on noble metal automotive catalysts", Applied Catalysis, 1991, 77 (2), pp. 175-186. 
[36] Yan, L., Yue, W., Wang, C., Wei, D., Xu, B., "Comparing tribological behaviors of sulfur- and phosphorus-free organomolybdenum additive with ZDDP and MoDTC", Tribology International, 2012, 53 pp. 150-158.

[37] Muraki, M., Yanagi, Y., \& Sakaguchi, K, "Synergistic effect on frictional characteristics under rolling-sliding conditions due to a combination of molybdenum dialkyldithiocarbamate and zinc dialkyldithiophosphate", Tribology international, 1997, 30(1), pp. 69-75.

[38] Kasrai, M., Cutler, J. N., Gore, K., Canning, G., Bancroft, G. M., \& Tan, K. H, "The chemistry of antiwear films generated by the combination of ZDDP and MoDTC examined by X-ray absorption spectroscopy", Tribology Transactions, 1998. 41(1), pp. 69-77.

[39] Miklozic, K. T., Forbus, T. R. and Spikes, H. A., "Performance of friction modifiers on ZDDP-generated surfaces", Tribology Transactions, 2007, 50(3), pp. 328-335.

[40] Rounds, F., "Effect of detergents on ZDP antiwear performance as measured in fourball wear tests", Lubrication Engineering, 1989, 45 (12), pp. 761-769.

[41] Minami, I., "Molecular Science of Lubricant Additives", Applied Sciences, 2017, 7 (5), pp. 445.

[42] Sniderman, D., "The chemistry and function of lubricant additives", Tribology and Lubrication Technology, 2017, 73 (11), pp. 18-29.

[43] Li, W., Kumara, C., Luo, H., Meyer, III, H. M., He, X., Ngo, D., Kim, S. H. and Qu, J., "Ultralow Boundary Lubrication Friction by Three-Way Synergistic Interactions among Ionic Liquid, Friction Modifier, and Dispersant", ACS Appl. Mater. Interfaces, 2020, 12, pp. 17077-17090.

[44] Johansson, S., Nilsson, P. H., Ohlsson, R. and Rosén, B. G., "Experimental friction evaluation of cylinder liner/piston ring contact", Wear, 2011, 271(3-4), pp. 625-633.

[45] Umer, J., Morris, N., Rahmani, R., Balakrishnan, S. and Rahnejat, H., "Nanoscale frictional characterisation of base and fully formulated lubricants based on activation energy components", Tribology International, 2020, 144: 106115.

[46] Gore, M., Morris, N., Rahmani, R., Rahnejat, H., King, P.D. and Howell-Smith, S., "A combined analytical-experimental investigation of friction in cylinder liner inserts under mixed and boundary regimes of lubrication", Lubrication Science, 2017, 29 (5), pp. 293316.

[47] Leighton, M., Morris, N., Rahmani, R., Rahnejat, H., "Surface specific asperity model for prediction of friction in boundary and mixed regimes of lubrication", Meccanica, 2017, 52 (1-2), pp. 21-33.

[48] ASTM standard D445, "Standard test method for kinematic viscosity of transparent and opaque liquids", West Conshohocken, PA, USA, 1996.

[49] Morris, N., Leighton, M., De la Cruz, M., Rahmani, R., Rahnejat, H., \& Howell-Smith, S., "Combined numerical and experimental investigation of the micro-hydrodynamics of chevron-based textured patterns influencing conjunctional friction of sliding contact", Proceedings of the Institution of Mechanical Engineers, Part J: Journal of Engineering 
Tribology, 2015, 229 (4), pp. 316-335.

[50] Wakuri, Y., Hamatake, T., Soejima, M., \& Kitahara, T., "Piston ring friction in internal combustion engines" Tribology international, 1992, 25(5), pp 299-308.

[51] Diaby, M., Sablier, M., Le Negrate, A., El Fassi, M., \& Bocquet, J., "Understanding carbonaceous deposit formation resulting from engine oil degradation", Carbon, 2009, 47(2), pp 355-366.

[52] Liu, W., Chen, S., "An investigation of the tribological behaviour of surface-modified ZnS nanoparticles in liquid paraffin", Wear, 2000, 238 (2), pp. 120-124.

[53] Bogunovic, L., Zuenkeler, S., Toensing, K., Anselmetti, D., "An Oil-Based lubrication system based on nanoparticular TiO2 with Superior Friction and Wear Properties", Tribology Letters, 2015, 59 (2), pp. 29.

[54] Umer, J., Saleem, F., Asim, M., Usman, M., Kamran, M. S., Alam, K. and Mohammadpour, M., "Thermal activation Eyring energy approach to characterise the dependence of nanoscale friction on the surface roughness", Tribology International, $2020,151,106532$.

[55] Spiller, S., Lenauer, C., Wopelka, T., \& Jech, M., "Real time durability of tribofilms in the piston ring-cylinder liner contact", Tribology International, 2017, 113, pp. 92-100.

[56] Willermet, P.A., "Some engine oil additives and their effects on antiwear film formation", Tribology Letters, 1998, 5(1), pp. 41-47.

[57] Plaza, S., "The Effect of Other Lubricating Oil Additives on the Adsorption of Zinc Diisobutyldithiophosphate on Fe and $\gamma$-Fe2O3 Powders", ASLE transactions, 1987, 30(2), pp. 241-247.

[58] Ramakumar, S.S.V., Rao, A.M. and Srivastava, S.P., "Studies on additive-additive interactions: Formulation of crankcase oils towards rationalization", Wear, 1992. 156(1), pp.101-120.

[59] Morina, A., Neville, A., Priest, M. and Green, J.H., "ZDDP and MoDTC interactions in boundary lubrication - the effect of temperature and ZDDP/MoDTC ratio", Tribology international, 2006, 39(12), pp.1545-1557.

[60] Morina, A. and Neville, A., "Understanding the composition and low friction tribofilm formation/removal in boundary lubrication", Tribology International, 2007, 40(10-12): pp. 1696-1704.

[61] Bouchet, M. D. B., Martin, J. M., Le Mogne, T., Bilas, P., Vacher, B., \& Yamada, Y., "Mechanisms of MoS2 formation by MoDTC in presence of ZnDTP: effect of oxidative degradation”, 2005, Wear, 258(11-12), 1643-1650.

[62] Martin, J.M., Grossiord, C., Varlot, K., Vacher, B. and Igarashi, J., "Synergistic effects in binary systems of lubricant additives: a chemical hardness approach", Tribology Letters, 2000, 8(4), pp.193-201. 
[63] Khaemba, D.N., Neville, A. and Morina, A., "New insights on the decomposition mechanism of Molybdenum DialkyldiThioCarbamate (MoDTC): a Raman spectroscopic study", RSC advances, 2016, 6(45), pp.38637-38646.

[64] Wei, J., Xue, Q. and Wang, H., "Effects of anti-wear additives on friction and wear properties of Cr2O3 coating", Tribology International, 1993, 26(4), pp. 241-244.

[65] Ghanbarzadeh, A., Piras, E., Nedelcu, I., Brizmer, V., Wilson, M.C.T., Morina, A., Dowson, D. and Neville, A., "Zinc dialkyl dithiophosphate antiwear tribofilm and its effect on the topography evolution of surfaces: A numerical and experimental study", Wear, 2016, 362-363, pp. 186-198. 